\title{
Ovariohisterectomia e ovariectomia em animais de companhia: revisão de literatura
}

\author{
Camila Debastiani, Marciele Mezzari
}

Universidade Estadual do Centro Oeste, Campus CEDETEG, Departamento de Medicina Veterinária. Guarapuava, Paraná. [came.db@ hotmail.com].

ISSUE DOI: $10.3738 / 1982.2278 .1141$

Hoje em dia as cirurgias de esterilização são as mais procuradas nas clínicas veterinárias. Isso devido aos seus vários benefícios, como controle da reprodução, redução dos sinais de estro, tratamento e prevenção de doenças. A técnica geralmente utilizada é a ovariohisterectomia $(\mathrm{OH})$, porém atualmente, a ovariectomia $(\mathrm{OE})$ vem se sobressaindo, pois já foram relatados várias vantagens em sua relação. Sabe-se que a OE por ser menos invasiva provoca níveis menores de hemorragia e dor trans e pós-operatória e melhor recuperação do animal. Bem como, previne praticamente as mesmas doenças que a $\mathrm{OH}$, exceto quando para isso é necessário remover o útero. Porém, como as afecções uterinas são poucas e raras não há uma indicação para a remoção do útero, sendo a remoção dos ovários suficiente. Neste trabalho são relatados benefícios e desvantagens de ambas as técnicas, como prevenção de doenças, níveis de dor, complicações a curto e longo prazo. Desta forma, objetiva tornar mais fácil a escolha da melhor técnica pelo médico veterinário.

Palavras-chave: técnicas de castração, cães e gatos, cirurgia. 